\title{
NEUROBEHAVIORAL GRAND ROUNDS－INTRODUCTION \\ Does near drowning in ice water prevent anoxic induced brain injury?
}

\author{
RAMONA O. HOPKINS ${ }^{1,2,3}$ \\ ${ }^{1}$ Psychology Department and Neuroscience Center, Brigham Young University, Provo, Utah \\ ${ }^{2}$ Department of Critical Care Medicine, Pulmonary and Critical Care Division, LDS Hospital, Salt Lake City, Utah \\ ${ }^{3}$ Department of Pulmonary and Critical Care Medicine, Intermountain Medical Center, Murray, Utah
}

\begin{abstract}
Cold water near-drowning is often thought to be neuroprotective in individuals with anoxia of a longer duration than that usually required to produce irreversible neurologic damage. There is a paucity of data in adults with cold water near-drowning that assess neuropsychological outcomes. Information regarding long-term effects of near cold water near-drowning on neuropathology, neuropsychological and neurobehavioral outcomes are uncommon. This paper provides an introduction to two cases of cold water near-drowning reported in this issue of JINS by Sameulson and colleagues and provides background information for interpretation of the findings of these cases in the context of outcomes following anoxia. (JINS, 2008, 14, 656-659.)
\end{abstract}

Keywords: Near cold water drowning, Hypothermia, Anoxia, Neuropsychological outcomes

\section{INTRODUCTION}

The incidence of cardiac arrest with anoxia and cerebral ischemia occurs in more than 400,000 cases per year in the United States, of which more than $80 \%$ of these patients are likely to have poor neurological outcomes (Geocadin et al., 2006; Zheng et al., 2001). Recent improvements in emergency and critical care medicine have resulted in approximately 200,000 cardiac resuscitations per year of which over 70,000 patients survive but constitute only $1 \%$ of those admitted to brain injury rehabilitation centers (Bachman \& Katz, 1997). Anoxia and ischemia can occur because of cardiac or respiratory arrest, open heart surgery, attempted hanging, complications of anesthesia, and near drowning.

Some brain regions are more vulnerable to the effects of anoxia/ischemia, particularly structures at the end of the vascular supply, with high metabolic rates (Brierley \& Graham, 1984), and/or proximity to structures that contain excitatory amino acids such as glutamate (Martin et al., 1994; Siesjo et al., 1989). Vulnerable brain regions include

Correspondence and reprint requests to: Ramona O. Hopkins, Ph.D., Psychology Department, 1082 SWKT, Brigham Young University, Provo, UT 84602. E-mail: mona_hopkins@byu.edu the neocortex, hippocampus, basal ganglia, cerebellum, primary visual cortex, frontal regions, and thalamus (Chalela et al., 2001). Anoxic brain injury results in focal and diffuse neuropathologic lesions and atrophy (Bachevalier \& Meunier, 1996; Caine \& Watson, 2000; Gale et al., 1999; Hopkins et al., 1995b) including lesions in the hippocampus (Manns et al., 2003a; Manns et al., 2003b), basal ganglia, cerebellum (Mascalchi et al., 1996), subcortical and periventricular white matter lesions (Parkinson et al., 2002) and atrophy of the corpus callosum (Porter et al., 2002). Generalized brain volume loss leading to ventricular enlargement and sulcal widening (Caine \& Watson, 2000) and hippocampal atrophy are also common (Hopkins et al., 1995b; Press et al., 1989). A review of anoxic brain injury $(N=90)$ found that $44 \%$ of individuals had cortical edema or atrophy, $33 \%$ had cerebellar lesions, $22 \%$ had basal ganglia lesions, 21\% had hippocampal atrophy, and 3\% had thalamic lesions (Caine \& Watson, 2000).

\section{Neurological and Neuropsychological Sequelae}

Poor neurological outcomes after brain injury include death, coma, vegetative state, severe neurologic disability (Jennett 
\& Bond, 1975), cognitive sequelae, and development of new psychiatric disorders (Bachevalier \& Meunier, 1996; Caine \& Watson, 2000). Neuropsychological deficits after anoxia or ischemia are heterogeneous and include agnosia (Farah, 1990), impaired memory (Hopkins et al., 2004; Manns et al., 2003a; Zola-Morgan et al., 1986), executive dysfunction (Hopkins et al., 1995a; Lezak, 1995), impaired visual-spatial skills (Barat et al., 1989), generalized cognitive impairments (Wilson, 1996), and motor disturbances (Lishman, 1998). Psychological and behavioral changes following anoxic brain injury often include euphoria, irritability, emotional volatility, depression, and anxiety (Bahrke \& Schukitt-Hale, 1993; Li et al., 2000).

\section{Mechanisms of Brain Injury}

Anoxia or ischemia causes a pathophysiological cascade that leads to neuronal damage and death (for reviews of the mechanisms see Biagas, 1999; Johnston et al., 2002). Mechanisms of anoxic induced neuronal injury include: (1) decreased ATP production without decreasing ATP utilization, resulting in energy depletion, ionic pump failure, $\mathrm{K}+$ outflow, and inflow of $\mathrm{Ca}^{2}+$ (Lutz \& Nilsson, 1994); (2) lactic acidosis caused by anaerobic metabolism (Siesjo, 1981); (3) excitotoxic damage caused by excessive glutamate release leading to increased neuronal firing, calcium influx, and neuronal death (Johnston et al., 2002); (4) increased calcium influx and intracellular accumulation of calcium due to ionic pump failure (Schurr et al., 1990); (5) the formation of oxygen radicals during reperfusion or reoxygenation (Biagas, 1999); (6) nitric oxide synthase leads to impaired neurotransmission, protein synthesis, and membrane peroxidation (Biagas, 1999); and (7) anoxia or ischemia also results in neuronal necrosis and/or apoptosis or programmed cell death (Beilharz et al., 1995; Steller, 1995).

\section{Therapeutic Hypothermia}

Recent research has generated considerable hope for better recovery following anoxia and ischemia using a variety of treatments. One such treatment is therapeutic hypothermia, which has shown improved neurological outcomes in 1 out of every 6 patients after cardiac arrest and cardiopulmonary resuscitation (Bernard et al., 2002; The Hypothermia after Cardiac Arrest Study Group, 2002). In principle a reduction in brain metabolic demands lead to decreased oxygen requirements and therefore reduced vulnerability to the neural effects of anoxia/ischemia. Animal models show that hypothermia inhibits multiple steps in the reperfusion phase of anoxic injury, including ATP consumption (Erecinska et al., 2003), reduced neuronal depolarization (Sick et al., 1999), decreased extra cellular glutamate concentrations (Busto et al., 1989), and decreased free radical production (Globus et al., 1995). A meta-analysis of 3 randomized controlled clinical trails in humans evaluated therapeutic hypothermia compared to normothermia found that therapeutic hypothermia was associated with good neurologic outcomes [relative risk of 1.68 (95\% CI 1.29-2.07)] (Holzer et al., 2005). The data mentioned earlier raise questions as to what if any role accidental hypothermia caused by coldwater immersion may play in preventing or reducing neuropsychological and psychiatric sequelae following near drowning.

\section{Cold Water Near-Drowning}

Cold water near-drowning is often believed to be neuroprotective in individuals with anoxia of a longer duration than that usually required to produce irreversible neurologic damage (Chochinov et al., 1998). Such neuroprotection is attributed to low core body temperatures, which reduce cerebral metabolic oxygen requirements and the mammalian dive reflex, which is believed to enhance the delivery of limited available oxygen stores to the brain (Chochinov et al., 1998). Most studies to date that assess outcome following cold water near-drowning have been conducted in children. A review of near-drowning and ice-water submersion in pediatric patients (13 less than 19 years of age) found 15 patients had a good outcome and 2 patients had a "fair to good outcome", but outcome was not defined and neuropsychological tests were not administered to these patients (Orlowski, 1987). There are few cases of near-drowning with cold-water submersion with poor outcomes reported in the literature (Orlowski, 1987). Orlowski suggests that cases with poor outcome are probably not reported whereas cases with good outcome are more commonly reported, resulting in a bias of good outcomes in the literature (Orlowski, 1987). One case of note, is that of R.D. who at 2.5 years of age was submerged in frigid water for $66 \mathrm{~min}$ utes with reportedly "good neurologic recovery" (Bolte et al., 1988). However, a neuropsychological evaluation 13 years later in this same individual found broad neurodevelopmental compromise, impaired memory, and executive function, despite a normal brain imaging (Hughes et al., 2002).

There is a paucity of data in adults with cold water neardrowning that assess outcome and only one study assessed neuropsychological function (Huckabee et al., 1996). The two cases of cold water near-drowning reported in this issue of JINS by Samuelson and colleagues assessed short term (a few days to months) and long-term (1.5 to 3.5 years) neuropsychological outcomes. Both cases had neuropsychological impairments that persisted over time. The neuropsychological findings of these two individuals with anoxic brain injury following cold water near-drowning are similar to those reported after anoxia from other etiologies (Bachevalier \& Meunier, 1996; Caine \& Watson, 2000; Hopkins et al., 2004; Manns et al., 2003a; Zola-Morgan et al., 1986). Further, these two individuals had symptoms of depression and behavioral changes. The rate of mood disorders after anoxic brain injury varies from $24 \%$ to $60 \%$ of cases, which is significantly higher than the prevalence rate in the general population (2\% to $9 \%$ major depression and $3 \%$ generalized anxiety), and the $12 \%$ rate observed in medical populations. 
Case 1 had a normal brain MRI scan 1.5 years after the accident, a finding that is similar to that reported by Orlowski (1987). However, brain imaging findings in near-drowning survivors are heterogeneous with abnormalities ranging from hemorrhageic infarctions to global atrophy (Fitch et al., 1985). Similarly, brain MRI findings in anoxic patients who were not near-drowning accidents include lesions in gray (e.g., basal ganglia, hippocampus, etc) and white matter, and global and focal atrophy (Bachevalier \& Meunier, 1996; Caine \& Watson, 2000; Hopkins et al., 2004; Manns et al., 2003a; Zola-Morgan et al., 1986). Whereas braining imaging was normal by radiologic report in Case 1, quantitative neuroimaging was not carried out (Bachevalier \& Meunier, 1996; Caine \& Watson, 2000; Gale et al., 1999; Hopkins et al., 1995b). Nonspecific brain damage may result in general volume reduction manifested by reduced gyral volume, increased sulcal space, passive increase in ventricular volume (i.e., hydrocephalus ex vacuo), increase in whole brain cerebral spinal fluid (CSF; Graham et al., 2002), and structural atrophy (e.g. hippocampus, basal ganglia, etc.). These changes may not be apparent visually but can be readily documented using quantitative MR analyses (Bigler, 2001). Thus, quantitative neuroimaging may detect important neuropathological changes in these cases that otherwise may not be detected.

The accidental hypothermia in these two cases likely contributed to preservation of life, but was not entirely neuroprotective, because both individuals had long-term neuropsychological and behavioral changes. The neuropsychological and neurobehavioral changes are similar to that observed after anoxia because of other etiologies. It is unclear if the accidental hypothermia reduced the extent and severity of the neuropsycholgoical and behavioral changes in these two cases, but it is certainly possible given the long duration of anoxia experienced by these two individuals. Research on the long-term effects of anoxia with and without cold water near-drowning on neuropathology, neuropsychological, and neurobehavioral outcomes is needed to better elucidate the effects of and possible benefits of accidental hypothermia.

\section{REFERENCES}

Bachevalier, J. \& Meunier, M. (1996). Cerebral ischemia: Are the memory deficits associated with hippocampal cell loss? Hippocampus, 6, 553-560.

Bachman, D. \& Katz, D.I. (1997). Anoxic-hypotensive brain injury and encephalitis. In V.M. Mills, J.W. Cassidy \& D.I. Katz (Eds.), Neurologic rehabilitation: A guide to diagnosis, prognosis, and treatment planning (pp. 145-176). Malden, MA: Blackwell Science, Ltd.

Bahrke, M.S. \& Schukitt-Hale, B. (1993). Effects of altitude on mood, behaviour, and cognitive functioning: A review. Journal of Sports Medicine, 16, 97-125.

Barat, M., Blanchard, J., \& Carriet, D. (1989). Les troubles neuropsychologiques des anozies cerebrales prolongees. Annales de Readaptation et de Medecine Physique, 32, 657-668.
Beilharz, E.J., Williams, C.E., Dragunow, M., Sirimanne, E.S., \& Gluckman, P.D. (1995). Mechanisms of delayed cell death following hypoxic-ischemic injury in the immature rat: Evidence for apoptosis during selective neuronal loss. Brain Research. Molecular Brain Research, 29, 1-14.

Bernard, S.A., Gray, T.W., Buist, M.D., Jones, B.M., Silvester, W., Gutteridge, G., \& Smith, K. (2002). Treatment of comatose survivors of out-of-hospital cardiac arrest with induced hypothermia. New England Journal of Medicine, 346, 557-563.

Biagas, K. (1999). Hypoxic-ischemic brain injury: Advancements in the understanding of mechanisms and potential avenues for therapy. Current Opinion in Pediatrics, 11, 223-228.

Bigler, E.D. (2001). Quantitative magnetic resonance imaging in traumatic brain injury. Journal of Head Trauma Rehabilitation, 16, 117-134.

Bolte, R.G., Black, P.G., Bowers, R.S., Thorne, J.K., \& Corneli, H.M. (1988). The use of extracorporeal rewarming in a child submerged for 66 minutes. JAMA, 260, 377-379.

Brierley, J.B. \& Graham, D.I. (1984). Cerebral complications of hypotensive anaesthesia in a healthy adult. Journal of Neurology, Neurosurgery, and Psychiatry, 25, 24-30.

Busto, R., Globus, M.Y., Dietrich, W.D., Martinez, E., Valdes, I., \& Ginsberg, M.D. (1989). Effect of mild hypothermia on ischemia-induced release of neurotransmitters and free fatty acids in rat brain. Stroke, 20, 904-910.

Caine, D. \& Watson, J.D. (2000). Neuropsychological and neuropathological sequelae of cerebral anoxia: A critical review. Journal of the International Neuropsychological Society, 6, 86-99.

Chalela, J.A., Wolf, R.L., Maldjian, J.A., \& Kasner, S.E. (2001). MRI identification of early white matter injury in anoxic-ischemic encephalopathy. Neurology, 56, 481-485.

Chochinov, A.H., Baydock, B.M., Bristow, G.K., \& Giesbrecht, G.G. (1998). Recovery of a 62-year-old man from prolonged cold water submersion. Annals of Emergency Medicine, 31, 127-131.

Erecinska, M., Thoresen, M., \& Silver, I.A. (2003). Effects of hypothermia on energy metabolism in mammalian central nervous system. Journal of Cerebral Blood Flow and Metabolism, 23, 513-530.

Farah, M. (1990). Visual Agnosia. Cambridge, MA: MIT Press.

Fitch, S.J., Gerald, B., Magill, H.L., \& Tonkin, I.L. (1985). Central nervous system hypoxia in children due to near drowning. Radiology, 156, 647-650.

Gale, S.D., Hopkins, R.O., Weaver, L.K., Bigler, E.D., Booth, E.J., \& Blatter, D.D. (1999). MRI, quantitative MRI, SPECT, and neuropsychological findings following carbon monoxide poisoning. Brain Injury, 13, 229-243.

Geocadin, R.G., Buitrago, M.M., Torbey, M.T., Chandra-Strobos, N., Williams, M.A., \& Kaplan, P.W. (2006). Neurologic prognosis and withdrawal of life support after resuscitation from cardiac arrest. Neurology, 67, 105-108.

Globus, M.Y., Alonso, O., Dietrich, W.D., Busto, R., \& Ginsberg, M.D. (1995). Glutamate release and free radical production following brain injury: Effects of posttraumatic hypothermia. Journal of Neurochemistry, 65, 1704-1711.

Graham, D.I., Gennarelli, T.A., \& McIntosh, T.K. (2002). Trauma. In D.I. Graham \& P.I. Lantos (Eds.), Greenfield's Neuropathology (7th ed., Vol. 2), (pp. 823-882). London: Edward Arnold; Hodder Headline Group.

Holzer, M., Bernard, S.A., Hachimi-Idrissi, S., Roine, R.O., Sterz, F., \& Mullner, M. (2005). Hypothermia for neuroprotection 
after cardiac arrest: Systematic review and individual patient data meta-analysis. Critical Care Medicine, 33, 414-418.

Hopkins, R.O., Gale, S.D., Johnson, S.C., Anderson, C.V., Bigler, E.D., Blatter, D.D., \& Weaver, L.K. (1995a). Severe anoxia with and without concomitant brain atrophy and neuropsychological impairments. Journal of the International Neuropsychological Society, 1, 501-509.

Hopkins, R.O., Kesner, R.P., \& Goldstein, M. (1995b). Item and order recognition memory in subjects with hypoxic brain injury. Brain and Cognition, 27, 180-201.

Hopkins, R.O., Myers, C.E., Shohamy, D., Grossman, S., \& Gluck, M. (2004). Impaired probabilistic category learning in hypoxic subjects with hippocampal damage. Neuropsychologia, 42, 524-535.

Huckabee, H.C., Craig, P.L., \& Williams, J.M. (1996). Near drowning in frigid water: A case study of a 31-year-old woman. Journal of the International Neuropsychological Society, 2, 256-260.

Hughes, S.K., Nilsson, D.E., Boyer, R.S., Bolte, R.G., Hoffman, R.O., Lewine, J.D., \& Bigler, E.D. (2002). Neurodevelopmental outcome for extended cold water drowning: A longitudinal case study. Journal of the International Neuropsychological Society, 8, 588-595.

Jennett, B. \& Bond, M. (1975). Assessment of outcome after severe brain damage. Lancet, 1, 480-484.

Johnston, M.V., Nakajima, W., \& Hagberg, H. (2002). Mechanisms of hypoxic neurodegeneration in the developing brain. Neuroscientist, 8, 212-220.

Lezak, M.D. (1995). Neuropsychological assessment (3rd ed.). New York: Oxford University Press.

Li, X.Y., Wu, X.Y., Fu, C., Shen, X.F., Wu, Y.H., \& Wang, T. (2000). Effects of acute mild and moderate hypoxia on human mood state. Space Medicine and Medical Engineering, 13, 1-5.

Lishman, W.A. (1998). Organic psychiatry: The psychological consequences of cerebral disorder (3rd ed.). Oxford: Blackwell Science Ltd.

Lutz, P.L. \& Nilsson, G.E. (1994). The brain without oxygen causes of failure and mechanisms for survival. Austin, TX: R.G. Landes Company.

Manns, J.R., Hopkins, R.O., Reed, J.M., Kitchener, E.G., \& Squire, L.R. (2003a). Recognition memory and the human hippocampus. Neuron, 37, 171-180.

Manns, J.R., Hopkins, R.O., \& Squire, L.R. (2003b). Semantic memory and the human hippocampus. Neuron, 38, 127-133.

Martin, R.L., Lloyd, H.G., \& Cowan, A.I. (1994). The early events of oxygen and glucose deprivation: Setting the scene for neuronal death? Trends in Neurosciences, 17, 251-257.
Mascalchi, M., Petruzzi, P., \& Zampa, V. (1996). MRI of cerebellar white matter damage due to carbon monoxide poisoning: Case report. Neuroradiology, 38(Suppl. 1), S73-S74.

Orlowski, J.P. (1987). Drowning, near-drowning, and ice-water submersions. Pediatric Clinics of North America, 34, 75-92.

Parkinson, R.B., Hopkins, R.O., Cleavinger, H.B., Weaver, L.K., Victoroff, J., Foley, J.F., \& Bigler, E.D. (2002). White matter hyperintensities and neuropsychological outcome following carbon monoxide poisoning. Neurology, 58, 1525-1532.

Porter, S.S., Hopkins, R.O., Weaver, L.K., Bigler, E.D., \& Blatter, D.D. (2002). Corpus callosum atrophy and neuropsychological outcome following carbon monoxide poisoning. Archives of Clinical Neuropsychology, 17, 195-204.

Press, G.A., Amaral, D.G., \& Squire, L.R. (1989). Hippocampal abnormalities in amnesic patients revealed by high-resolution magnetic resonance imaging. Nature, 341, 54-57.

Schurr, A., Lipton, P., West, C.A., \& Rigor, B.M. (1990). The role of energy in metabolism and divalent cations in the neurotoxicity of excitatory amino acids in vitro. In J. Krieglstein (Ed.), Pharmacology of cerebral ischemia (pp. 217-226). Boca Raton, FL: CRC Press LLC.

Sick, T.J., Xu, G., \& Perez-Pinzon, M.A. (1999). Mild hypothermia improves recovery of cortical extracellular potassium ion activity and excitability after middle cerebral artery occlusion in the rat. Stroke, 30, 2416-2421 (discussion 2422).

Siesjo, B.K. (1981). Cell damage in the brain: A speculative synthesis. Journal of Cerebral Blood Flow and Metabolism, 1, $155-185$

Siesjo, B.K., Bengtsson, F., Grampp, W., \& Theander, S. (1989). Calcium, excitotoxins, and neuronal death in the brain. Annals of the New York Academy of Sciences, 568, 234-251.

Steller, H. (1995). Mechanisms and genes of cellular suicide. Science, 267(5203), 1445-1449.

The Hypothermia after Cardiac Arrest Study Group. (2002). Mild therapeutic hypothermia to improve the neurologic outcome after cardiac arrest. New England Journal of Medicine, 346, $549-556$

Wilson, B.A. (1996). Cognitive functioning of adult survivors of cerebral hypoxia. Brain Injury, 10, 863-874.

Zheng, Z.J., Croft, J.B., Giles, W.H., \& Mensah, G.A. (2001). Sudden cardiac death in the United States, 1989 to 1998. Circulation, 104, 2158-2163.

Zola-Morgan, S., Squire, L.R., \& Amaral, D.G. (1986). Human amnesia and the medial temporal region: Enduring memory impairment following a bilateral lesion limited to field CA1 of the hippocampus. Journal of Neuroscience, 6, 2950-2967. 